\title{
PENERAPAN PEMBELAJARAN KONTEKSTUAL PADA KALKULUS 2 BAHASAN VOLUM BENDA PUTAR
}

\author{
Yulia Romadiastri \\ Dosen Jurusan Tadris Matematika FITK IAIN Walisongo
}

\begin{abstract}
Abstrak
Salah satu bahasan pada mata kuliah Kalkulus 2 adalah aplikasi integral tentu, yang di dalamnya terdapat materi menentukan volum benda putar. Materi ini cukup sulit mengingat mahasiswa harus dapat memvisualisasikan daerah yang berupa bidang datar ke dalam ruang dimensi tiga. Selain itu, ada beberapa metode yang digunakan untuk menentukan volum benda sesuai dengan bentuk bangun ruang yang dihasilkan. Dengan menerapkan pembelajaran kontekstual diharapkan dapat membantu mahasiswa dalam memvisualisasikan dan menentukan metode yang sesuai untuk mencari volum benda putar tersebut.
\end{abstract}

Kata Kunci: volum benda putar, pembelajaran kontekstual 


\section{PENDAHULUAN}

Mata kuliah Kalkulus 2 adalah salah satu mata kuliah wajib yang harus ditempuh oleh semua mahasiswa Matematika. Materi pada Kalkulus 2 ini merupakan lanjutan dari Kalkulus 1 yang juga merupakan rangkaian materi dasar pada matematika yang harus dikuasai oleh mahasiswa. Tidak hanya pada jurusan matematika saja, mahasiswa jurusan eksak di luar matematika juga harus menempuh mata kuliah ini.

Jika pada Kalkulus 1 bahasannya adalah tentang fungsi, limit, turunan, dan penerapan turunan, maka pada Kalkulus 2 materinya berupa lanjutan dari turunan yaitu integral. Diawali dari anti turunan, anti diferensial, integral tak tentu, integral tentu, penerapan integral tentu, dan teknik-teknik pengintegralan. Penerapan integral tentu sangat luas digunakan pada berbagai bidang diantaranya fisika, kimia, biologi, ekonomi, pertanian, dan bidang-bidang lain. Sedangkan penerapan integral tentu di bidang matematika sendiri juga cukup banyak yaitu mencari luas daerah, menghitung volum benda putar, mencari panjang busur, dan mencari luas permukaan.

Dalam menghitung volum benda putar, tidak bisa sekedar menggunakan rumus volum saja kemudian diperoleh hasilnya. Fungsi yang menjadi batas daerah perlu disketsakan kemudian dari daerah yang terbentuk diputar pada sumbu putar tertentu sehingga hasil putarnya membentuk suatu bangun ruang tertentu yang mungkin saja bentuknya tidak beraturan. Selain itu, konsep integral tentu sendiri berasal dari jumlah Riemann yang cukup abstrak bagi kebanyakan mahasiswa. Hal inilah, yang membuat banyak mahasiswa kesulitan karena selain proses visualisasi yang tidak mudah digabungkan dengan konsep jumlah Riemann yang cukup rumit. Oleh karena itu, diperlukan pembelajaran yang kontekstual untuk membantu mahasiswa dalam memahami konsep ini dan mempermudah dalam visualisasi dari dimensi dua menjadi dimensi tiga. 


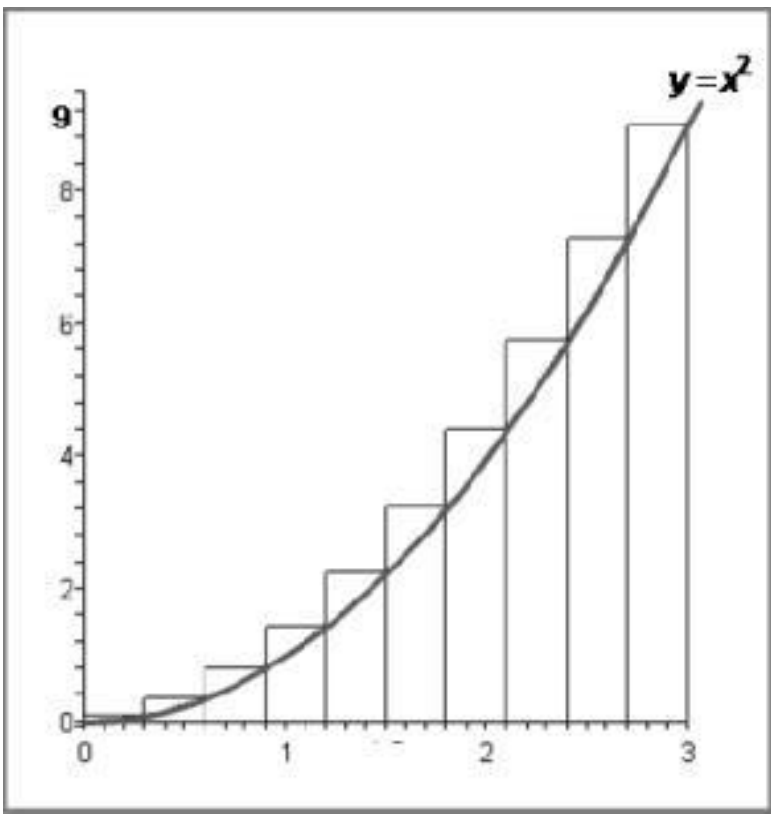

\section{Pembelajaran Kontekstual}

Pembelajaran kontekstual merupakan konsep belajar yang membantu guru mengaitkan antara materi yang diajarkan dengan situasi dunia nyata dan mendorong siswa membuat hubungan antara pengetahuan yang dimilikinya dengan penerapannya ke dalam kehidupan mereka sehari-hari. ${ }^{1}$ Dari konsep demikian diharapkan proses pembelajaran menjadi lebih bermakna bagi peserta didik.

Filosofi yang mendasari pengembangan pendekatan kontekstual atau Contextual Teaching and Learning adalah pengetahuan dibangun oleh manusia sedikit demi sedikit, yang hasilnya diperluas melalui konteks yang terbatas dan tidak sekonyongkonyong. Pengetahuan bukanlah seperangkat fakta, konsep, atau kaidah yang siap untuk diambil atau diingat. Manusia harus mengkonstruksi pengetahuan itu dan memberi makna me-

${ }^{1}$ Sumargiyani, 2006, Penerapan Pembelajaran Kontekstual pada Pembahasan Volume Benda Putar dengan Pembelajaran Kontekstual, Jogjakarta 
lalui pengalaman nyata. ${ }^{2}$

Matematika memiliki sifat yang abstrak yang dalam mengajarkan perlu diupayakan supaya menjadi lebih konkrit. Ahmadi mengemukakan bahwa masalah-masalah yang tidak semuanya dapat dipecahkan secara abstrak, yaitu masalah yang sangat pelik dibutuhkan suatu upaya agar yang dihadapi menjadi lebih konkrit. ${ }^{3}$ Dengan berpikir lebih konkrit akan memudahkan mahasiswa dalam menerima materi.

Menurut hudoyo, materi pelajaran dapat berinteraksi dengan siswa bila materi itu sesuai dengan perkembangan intelektual siswa dan cocok dengan struktur kognitif siswa. ${ }^{4}$ Adapun cirri-ciri pembelajaran kontekstual meliputi: (1) berbasis masalah, (2) menggunakan konteks ganda, (3) membangkitkan keteraturan belajar, (4) siswa menjadi bagian dari konteks, (5) belajar dalam konteks sosial, dan (6) menggunakan penilaian autentik. $^{5}$

\section{Volum Benda Putar}

Salah satu penerapan integral di bidang matematika sendiri adalah menentukan volum benda putar. Yang dimaksud benda putar di sini adalah hasil perputaran suatu daerah yang diputar pada satu sumbu putar tertentu. Semisal pada gambar berikut adalah sketsa dari suatu fungsi pada bidang Cartesius. Daerah yang diarsir adalah daerah yang dibatasi oleh fungsi dan sumbu $\mathrm{X}$ dari batas 0 sampai titik $a$.

2 Depdiknas, 2003, Pendekatan Kontekstual (Contextual Teaching and Learning), Jakarta

${ }^{3}$ Ahmadi, Abu, 1982, Psikologi Umum, Jakarta: Rineka Cipta

${ }^{4}$ Hudojo, Herman, 1979, Pengembangan Kurikulum Matematika dan Pelaksanaannya di depan Kelas, Surabaya

${ }^{5}$ Depdiknas, 2003, Pendekatan Kontekstual (Contextual Teaching and Learning), Jakarta 


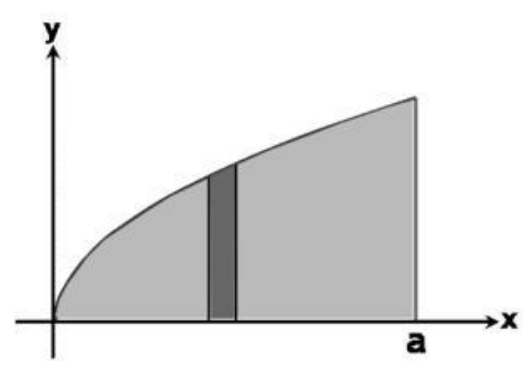

Jika daerah yang diarsir tersebut diputar mengelilingi sumbu X, maka akan terbentuk benda putar yang bentuknya seperti gambar berikut. Benda putar tersebut dapat dihitung volumnya dengan menggunakan integral tentu. Bisa dilihat bahwa benda putar di sini bisa berbentuk apa saja dan tidak beraturan mengikuti sketsa fungsi yang diberikan. Selain itu, sumbu putar yang utama adalah sumbu $X$ dan sumbu $Y$, tetapi pada perkembangan lebih lanjut, sumbu putar bisa merupakan garis sebarang.

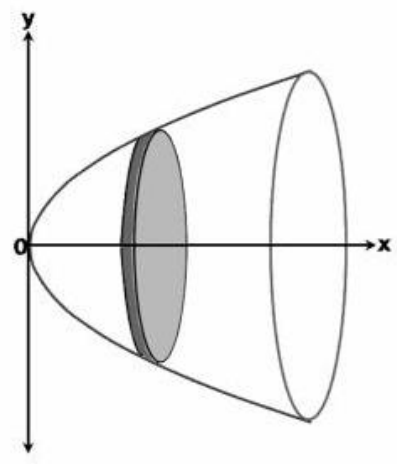

Diberikan fungsi $f(x)=x^{2}, x \in \mathrm{i}$ RR dan garis $y=4$. Jika fungsi dan garis tersebut digambar pada bidang Cartesius, maka daerah yang dibatasi oleh fungsi $f$, garis $y=4$, dan sumbu $Y$ diperlihatkan pada bagian yang diarsir. ${ }^{6}$

${ }^{6}$ Purcell, E.J. \& Varberg, D. 1987. Kalkulus dan Geometri Analitis. (Diterjemahkan oleh I Nyoman, Bana Kartasasmita, dan Rawuh). Jilid 1. Jakarta: Penerbit Erlangga 


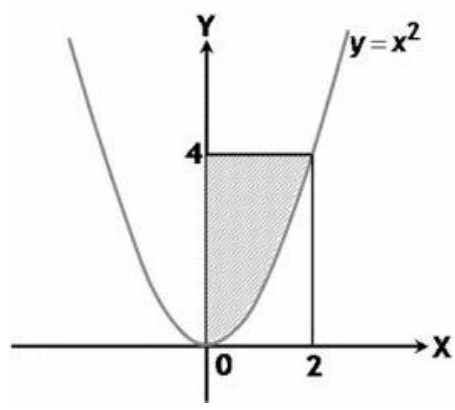

Jika daerah yang diarsir tersebut diputar mengelilingi sumbu $\mathrm{Y}$, maka akan diperoleh benda putar seperti berikut.

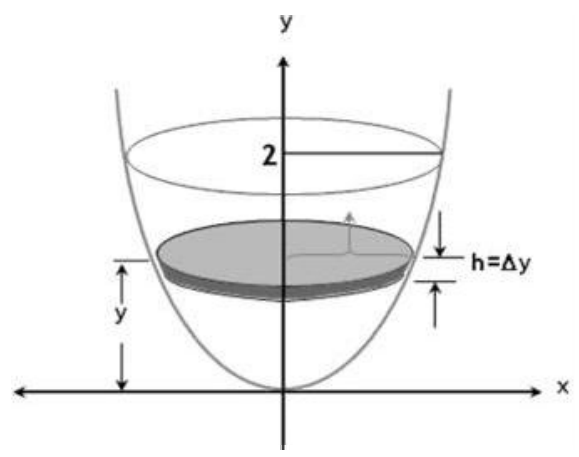

Beberapa contoh di atas adalah contoh dari fungsi yang relatif sederhana, akan tetapi permasalahan yang ada bisa melibatkan lebih dari satu fungsi dengan bentuk yang bervariasi. Karena itu, diperlukan pembelajaran kontekstual untuk membantu mahasiswa dalam memvisualisasikan sketsa-sketsa tersebut ke dalam bentuk bangun ruang dan menentukan metode yang sesuai untuk menentukan volum benda putar.

\section{Penerapan Pembelajaran Kontekstual pada Bahasan Volum Benda Putar}

Berdasarkan paparan di atas, maka pembelajaran Kalkulus 2 pada bahasan Volum Benda Putar dapat dilakukan dengan cara sebagai berikut: 
(1) Berbasis masalah

Sebelum penjelasan tentang metode mencari volum benda putar berikut rumus-rumusnya, diberikan penjelasan kepada mahasiswa permasalahan mencari volum benda yang bentuknya beraturan yang ada di lingkungan sekitar seperti bola, tabung, kerucut, dan lain-lain. Kemudian disampaikan bahwa bangun ruang ada yang bentuknya tak beraturan di lingkungan sekitar, misalnya bola lampu, galon, dan sebagainya.

(2) Menggunakan konteks ganda

Masalah yang disampaikan diupayakan mempunyai konteks ganda, yaitu yang berkaitan dengan mata kuliah lain atau yang terkait dengan pengalaman mahasiswa sendiri. Untuk langkah pertama, bisa diawali dengan menghitung volum tabung, bola, dan kerucut. Kemudian setelah itu, bisa ditingkatkan kesulitannya dengan mencari benda yang tak beraturan, semisal tabung yang dilubangi atau kerucut terpancung dan lain sebagainya. Bahasan ini disampaikan dengan asumsi bahwa mahasiswa tentu sudah mempunyai pemahaman dan pengalaman tentang volum benda beraturan tersebut.

(3) Membangkitkan keteraturan belajar

Dalam proses belajar mengajar perlu diupayakan dan dirancang supaya mahasiswa menjadi aktif, kreatif dan dinamis dalam menghadapi dan menyelesaikan permasalahan. Hal ini dapat berjalan jika pengajar mempersiapkan materi dan metode secara matang. Bagaimana para pengajar memberikan motivasi dengan percikan semangat, maka mahasiswa akan terpacu dengan sendirinya untuk aktif dan berusaha keras untuk menemukan penyelesaian dari maslah yang dihadapi.

(4) Siswa menjadi bagian dari konteks

Dalam pembelajaran ini, mahasiswa menjadi bagian dari konteks, karena mereka diminta mencari bentuk-bentuk benda baik yang beraturan dan tak beraturan dari lingkungan sekitar. 
(5) Belajar dalam konteks sosial

Di dalam pembelajaran ini juga dirancang agar mahasiswa dapat saling berdiskusi mengemukakan pendapat, bertanya dan mendebat pendapat orang lain. sehingga muncul interaksi antar mahasiswa, dan diharapkan dapat mengaktifkan setiap mahasiswa.

(6) Menggunakan penilaian autentik

Untuk melihat kemajuan mahasiswa dapat dilakukan dengan kuis atau tugas.

Selain memenuhi enam ciri pembelajaran kontekstual di atas, penggunaan media juga sangat membantu. Karena materi ini banyak menggunakan gambar, maka penggunaan media seperti powerpoint juga dapat dimanfaatkan. Selain mudah, media powerpoint dapat memuat gambar dan juga menampilkan animasi yang menarik, sehingga diharapkan mahasiswa dapat lebih memahami konsep dari Jumlah Riemann dan perhitungan volum benda putar. Berikut contoh penggunaan powerpoint pada Kalkulus 2 bahasan volum benda putar.

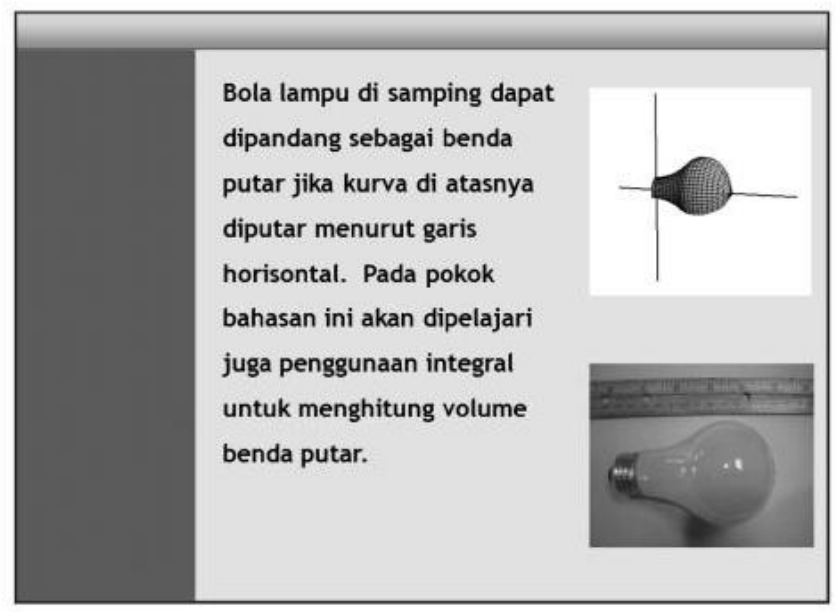

Dari benda-benda di lingkungan sekitar, dapat dipandang sebagai daerah yang jika diputar pada suatu sumbu putar ter- 
tentu menghasilkan benda putar yang dapat dicari volumnya. Hal ini memudahkan mahasiswa dalam memvisualisasikan benda-benda tak beraturan yang terjadi dari fungsi-fungsi yang rumit. Di sinilah letak kontekstual dari pembelajaran Kalkulus 2 terutama pada bahasan volum benda putar.

Pada prinsipnya, ada tiga metode dalam mencari volum benda putar berdasarkan dari bentuk bendanya. Terkadang mahasiswa mengalami kesulitan menentukan metode mana yang harus digunakan ketika menjumpai suatu soal. Dengan bantuan visualisasi dari powerpoint ini, diharapkan dapat membantu mahasiswa menentukan metode yang tepat dalam menyelesaikan suatu masalah.
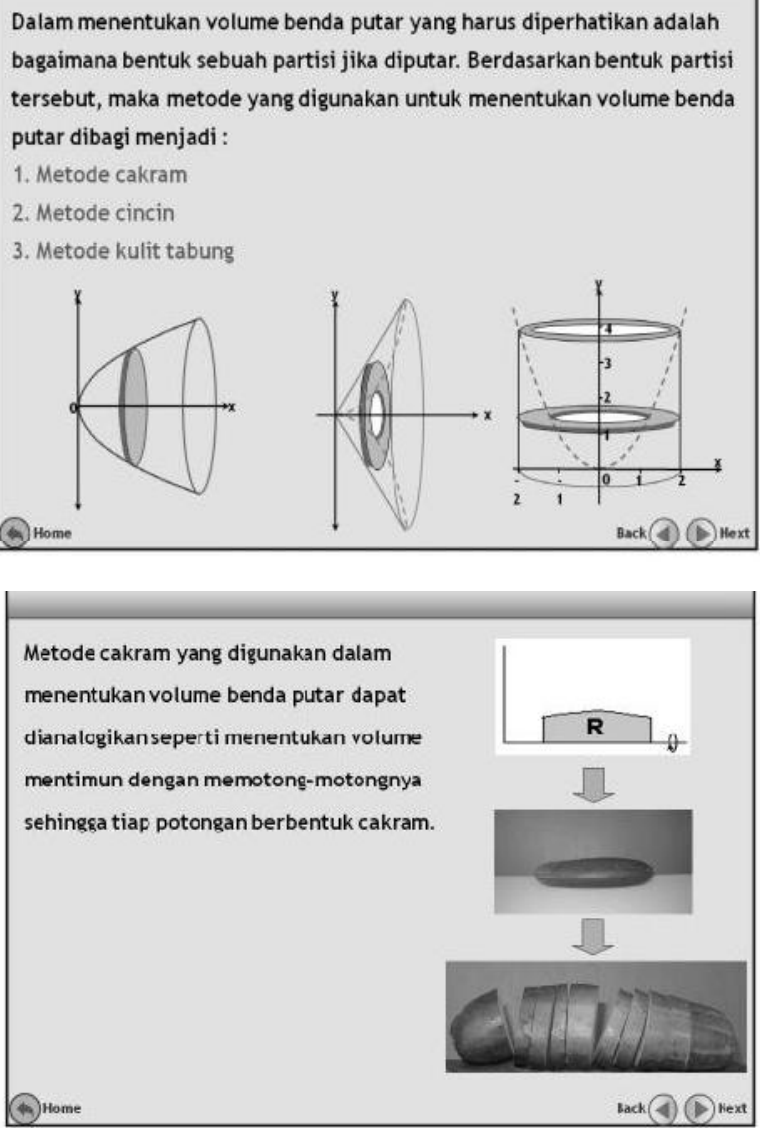
Analogi yang digunakan pada masing-masing metode dipilih yang sesuai dengan karakteristik dan banyak dijumpai di lingkungan sekitar. Seperti pada metode cakram dianalogikan dengan memotong-motong timun sehingga tiap potongannya berbentuk cakram atau biasa disebut tabung. Akan lebih mudah mencari volum tabung kemudian dijumlahkan sehingga diperoleh volum timun secara utuh. Potongan timun yang dimaksudkan sebenarnya adalah konsep dari partisi pada jumlah Riemann.
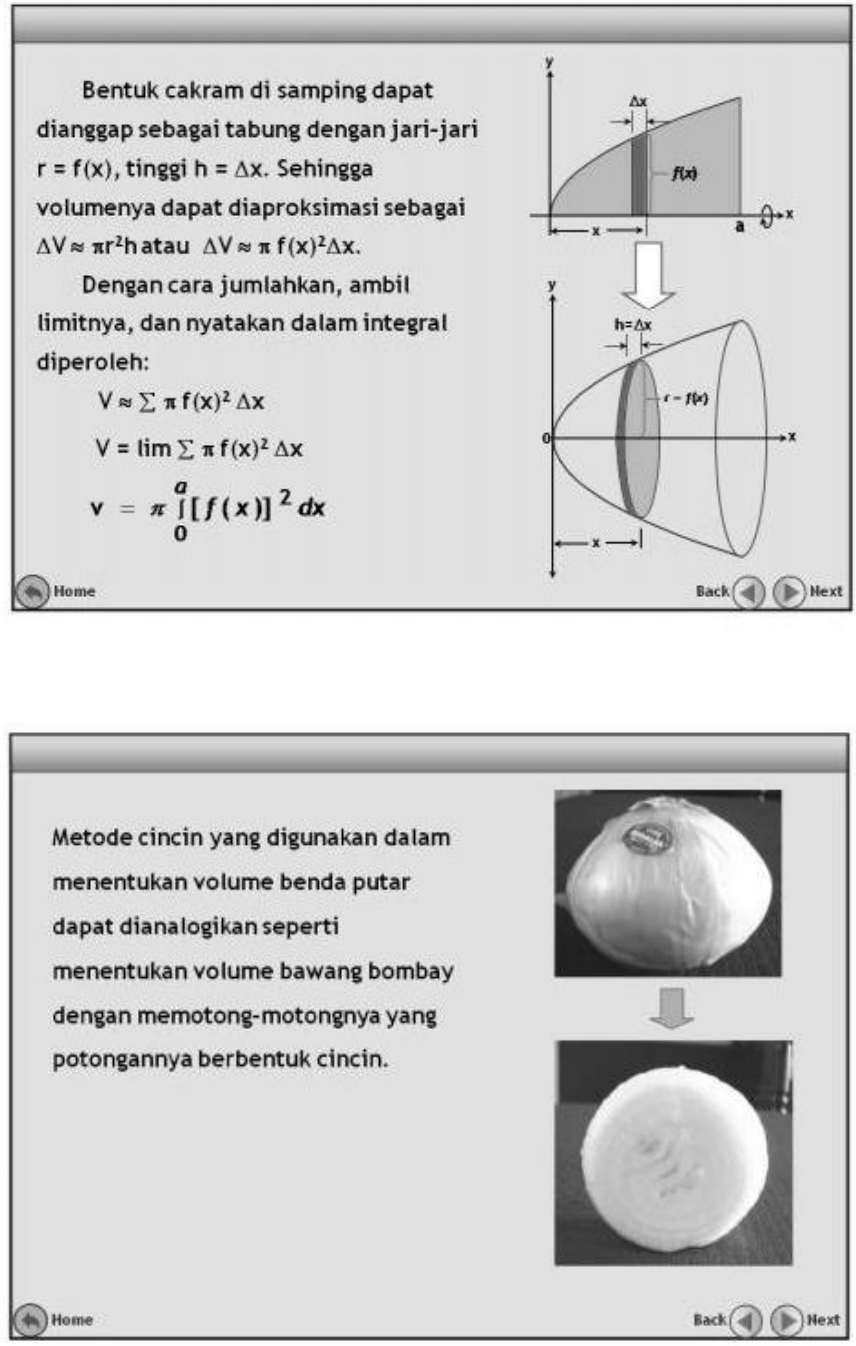
Pada metode cincin, analogi yang digunakan adalah bawang Bombay, karena ketika diiris melintang potongan akan dapat dilepas yang masing-masing berbentuk cincin. Ini sesuai dengan metode cincin yang bentuk partisinya berupa cincin.
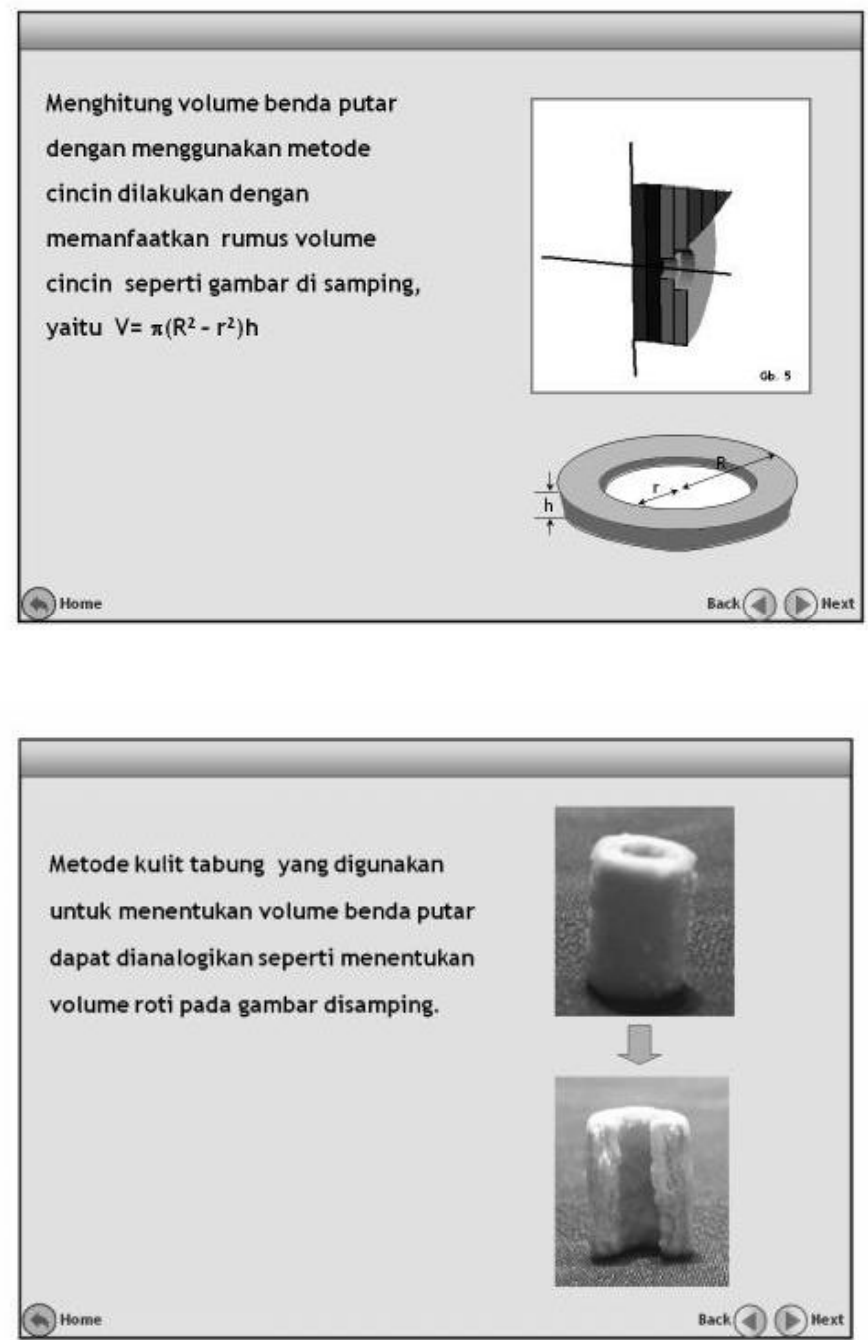

Sedangkan pada metode kulit tabung atau ada juga yang menyebut dengan metode sel silinder, digunakan analogi roti yang berbentuk seperti pipa dengan lubang di tengah, kemudian diiris secara horizontal. 


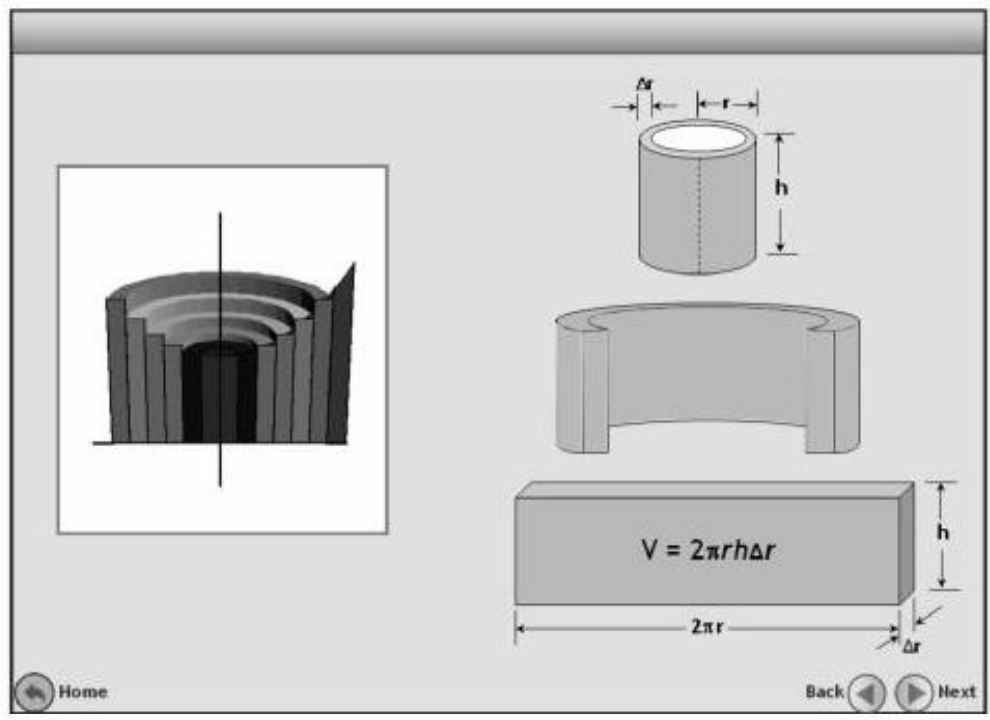

\section{KESIMPULAN}

Materi Kalkulus 2 yang cukup abstrak terutama pada bahasan volum benda putar memang memerlukan daya imajinasi yang tinggi, karena dibutuhkan kemampuan berimajinasi dari daerah dua dimensi yang diputar pada suatu sumbu putar tertentu sehingga menghasilkan bangun ruang tiga dimensi dari hasil perputarannya. Diperlukan satu pembelajaran yang kontekstual pada materi ini untuk mengkonkritkan konsep jumlah Riemann yang abstrak. Melalui benda-benda di lingkungan sekitar yang mudah didapat, satu pemahaman konsep yang penting dalam matematika dapat disampaikan kepada mahasiswa. Tentunya masih diperlukan perbaikan dan pengembangan lagi sehingga dapat diperoleh hasil yang lebih maksimal. 


\section{DAFTAR PUSTAKA}

Ahmadi, Abu, 1982, Psikologi Umum, Jakarta: Rineka Cipta

Depdiknas, 2003, Pendekatan Kontekstual (Contextual Teaching and Learning), Jakarta

Hudojo, Herman, 1979, Pengembangan Kurikulum Matematika dan Pelaksanaannya di depan Kelas, Surabaya

Purcell, E.J. \& Varberg, D. 1987. Kalkulus dan Geometri Analitis. (Diterjemahkan oleh I Nyoman, Bana Kartasasmita, dan Rawuh). Jilid 1. Jakarta: Penerbit Erlangga

Sumargiyani, 2006, Penerapan Pembelajaran Kontekstual pada Pembahasan Volume Benda Putar dengan Pembelajaran Kontekstual, Jogjakarta 